\title{
Neuron-specific enolase in the intestinal wall in Crohn's disease
}

\author{
Busikova-Malenovska $\mathrm{P}^{1}$, Danis $\mathrm{D}^{1}$, Bencat $\mathrm{M}^{4}$, Galfiova $\mathrm{P}^{3}$, Kopani $\mathrm{M}^{2}$, Labajova $\mathrm{V}^{2}$, \\ El Hassoun $\mathrm{O}^{4}$, Porubsky $\mathrm{J}^{2}$, Galatova $\mathrm{J}^{5}$ \\ Cytopathos, Institute of Pathological Anatomy, Slovak Health University, Bratislava, Slovakia. \\ malenovska@cytopathos.sk
}

\begin{abstract}
The authors described the localization of neuron-specific enolase in the intestinal wall in Crohn's disease. We have used samples obtained by biopsy from the colon lining of five people affected by Crohn's disease for our examination. We have processed samples using the formol paraffin technique. From paraffin blocks, we have prepared histological sections approximately $5 \mu \mathrm{m}$ thick. For immunohistochemic examinations, we have revitalised the sections by acquiring the heat-induced epitope. We detected NSE by monoclonal mouse antibodies against human neuron-specific enolase, clone BBS/NC/VI-H14 (DakoCytomation, Denmark) (Fig. 4, Ref. 7). Text in PDF www.elis.sk.

Key words: morphology of intestinal innervation, Crohn's disease, neuron-specific enolase.
\end{abstract}

Anatomical and functional relationships of various barriers during inflammatory bowel diseases affect among others also the innervation of the intestinal wall. Crohn's disease is one of the major units of chronic intestinal inflammation. Surprisingly, in the PubMed database, we can only find one publication that deals with the detection of neuron-specific enolase, and Crohn's disease (Schneider et al 2001).

\section{Materials and methods}

We have used samples obtained by biopsy from the colon lining of five people affected by Crohn's disease for our examination. We have processed samples using the formol paraffin technique. From paraffin blocks, we have prepared histological sections approximately $5 \mu \mathrm{m}$ thick. For immunohistochemic examinations, we have revitalised the sections by acquiring the heat-induced epitope. We detected NSE by monoclonal mouse antibodies against human neuron-specific enolase, clone BBS/NC/VI-H14 (DakoCytomation, Denmark).

\section{Results}

In the submucosis, there are a number of NSE-positive nerve fibres of which some thinly, some densely reach the deepest lay-

${ }^{1}$ Cytopathos, Institute of Pathological Anatomy, Slovak Health University, Bratislava, Slovakia, ${ }^{2}$ Institute of Pathological Anatomy, Faculty of Medicine, Comenius University, Bratislava, Slovakia, ${ }^{3}$ Institute of Histology and Embryology, Faculty of Medicine, Comenius University, Bratislava, Slovakia, ${ }^{4}$ Alpha-medical, a.s., Laboratory of Pathological Anatomy, Martin, Slovakia, and ${ }^{5}$ Institute of Foreign Language, Faculty of Medicine, Comenius University, Bratislava, Slovakia

Address for correspondence: P. Malenovska-Busikova, MD, Hviezdoslavova 31, SK-901 01 Malacky, Slovakia.

Phone: +421.918402476

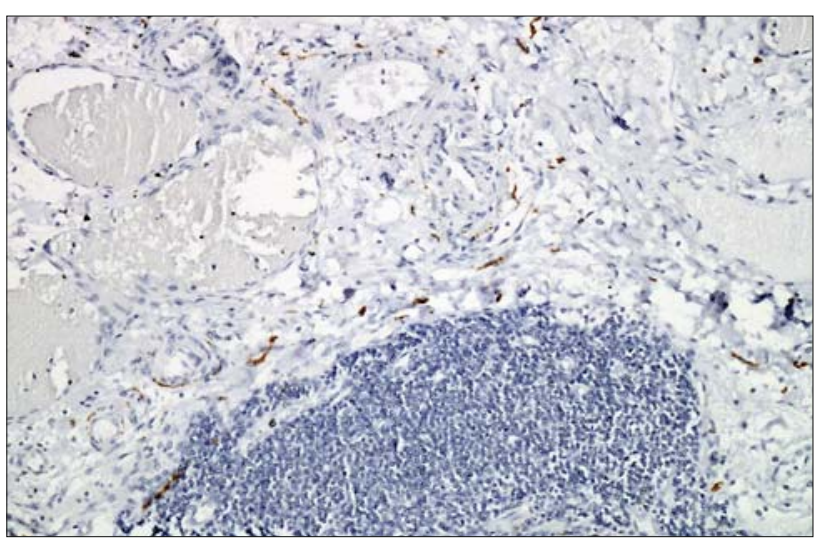

Fig. 1. Follicle of lymphoid tissue in the submucosis. NSE + fibres can be seen in its surrounding and on its borders. Fibres do not enter into the depth of the NSE1 follicle. NSE x100.

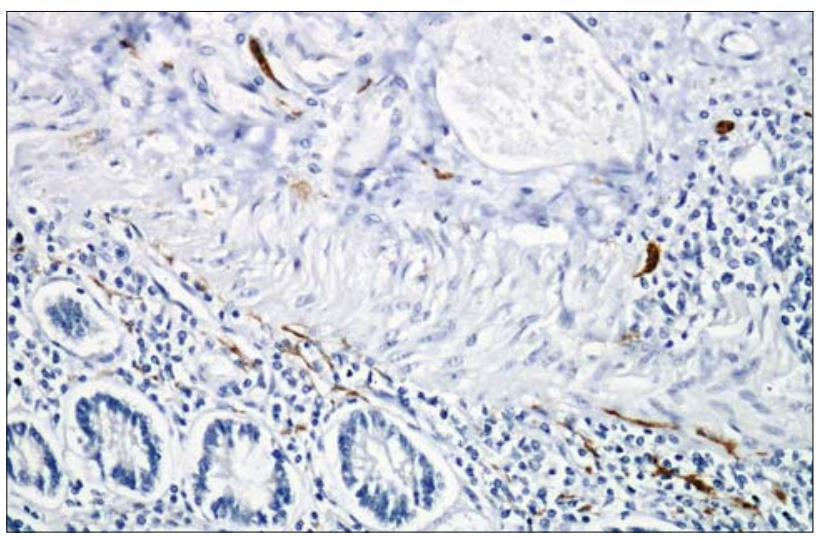

Fig. 2. NSE + fibres are numerous in lamina propria mucosae. It is very rare that huge lamina muscularis mucosae contains such fibres. In the submucosis - focuses of lymphoid cells or granulation tissue. In that, sometimes. 


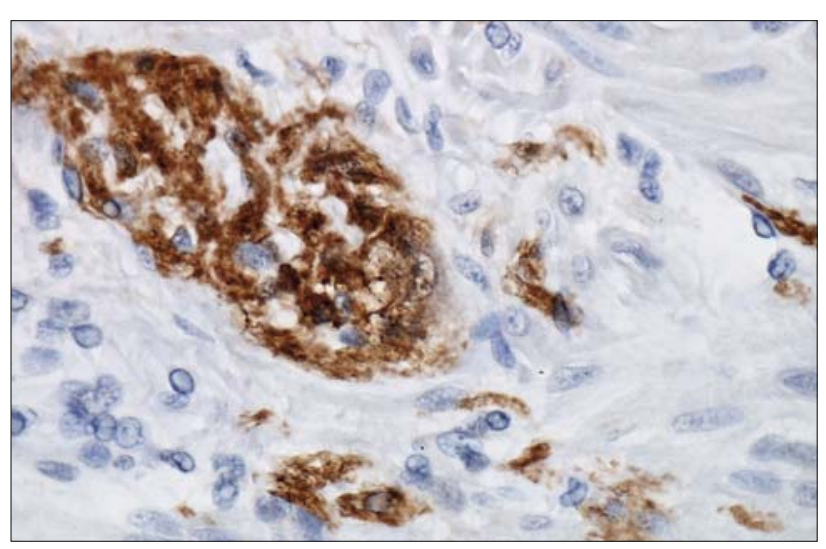

Fig. 3 NSE+ ganglion, surrounded by granulation tissue. Also in granulation tissue, positive cells and fibres can be seen. NSE $x 400$.

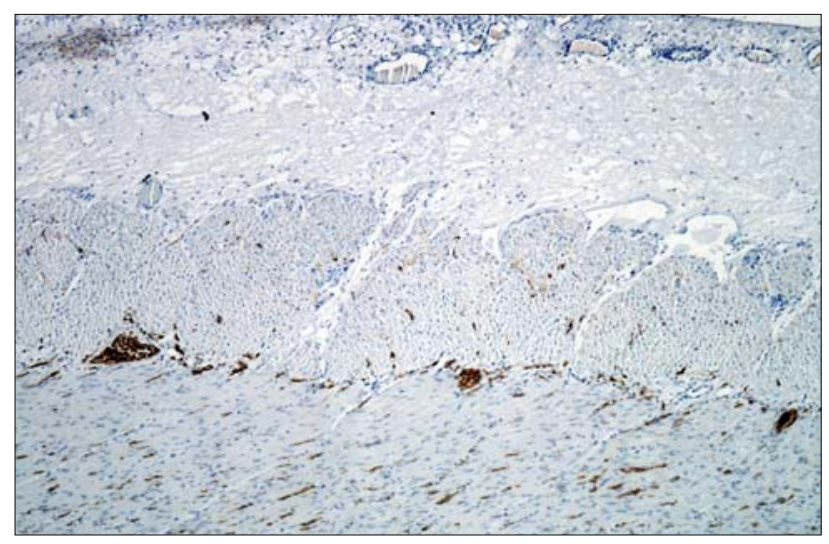

Fig. 4. Between circular and longitudinal muscle: NSE + small ganglia. Longitudinal muscle layer contains more NSE + fibres than the circular one. In the sclerotic lamina propria mucosae NSE+ there are no cells. NSE x100.

ers of lamina propria mucosae over lamina muscularis mucosae. There they sometimes touch the aggregates of lymphoid cells, but they do not enter them directly (Fig. 1). On the border of circular and longitudinal muscles, follicles of positively responding cells can be seen. In both circular and longitudinal muscle layers, the positively responding cells and fibres are scattered, of which more abundant are in the longitudinal layer (Fig. 2). In the layer of glands, some of the fibres touch membrana basalis glands and crypts (Fig. 3). In lamina muscularis mucosae, such fibres are not present. In unaffected areas of intestines of people with Crohn's disease, the number of enteroglial cells decreases. In colitis ulcerosa, Cajal cells and enteroglial cells rise in the affected intestinal wall muscle (Fig. 4). With regard to the size of our set, we cannot form an unambiguous opinion in relation to the issue.

\section{Discussion}

Particularities of the nervous systems of people suffering from chronic idiopathic inflammatory bowel disease are described in a variety of studies. Villanacci et al (2008) systematically analyzes the density and distribution of neurons and enteroglial and inter- stitial cells of Cajal in different nerve plexuses of people with Crohn's disease and colitis ulcerosa as well as those in control sets of samples from unaffected areas of the intestines using antibodies against NSE. They generally describe the growth of the number of nerve cells and enteroglia. Antibodies against NSE may also be used to identify neuroendocrine cells. Analysis of information on NSE in relation to intestines provides 90 sources in the PubMed. gov database. With the exception of one publication cited in the introduction, no information on NSE-positive neurones in relation to Crohn's disease is available to us. Thereof, only some provide information on human NSE in this relationship. Most are related to the description of neuroendocrine intestinal tumours (e.g. Turri Fangaresi, 1988 and Matysiak-Budnik et al, 2008). The most detailed analysis of intestinal wall innervation of humans with antibodies against NSE is described by Kubíková et al (2009) in the wall of human appendix. Mostly, however, we rely on the information obtained from animals (e.g. Kleinschmidt et al, 2011 and Vetuschi et al, 2006).

\section{References}

1. Schneider J, Jehle EC, Starlinger MJ, Neunlist M, Michel K, Hoppe S, Schemann M. Neurotransmitter coding of enteric neurones in the submucous plexus is changed in non-inflamed rectum of patients with Crohn's disease. Neurogastroenterol Motil 2001; 13 (3): 255-264.

2. Villanacci V, Bassotti G, Nascimbeni R, Antonelli E, Cadei M, Fisogni S, Salerni B, Geboes K. Enteric nervous system abnormalities in inflammatory bowel disease Neurogastroenterol Motil 2008; 20 (9): 1009-1016.

3. Turri L, Fangaresi E. Multiple duodenal and ampullary carcinoids and von Recklinghausen's neurofibromatosis. Chir Ital 1988; 40 (4-5): 285-294.

4. Matysiak-Budnik T, Moura IC, Arcos-Fajardo M, Lebreton C, Ménard S, Candalh C, Ben-Khalifa K, Dugave C, Tamouza H, van Niel G, Bouhnik Y, Lamarque D, Chaussade S, Malamut G, Cellier C, Cerf-Bensussan N, Monteiro RC, Heyman M. Secretory IgA mediates retrotranscytosis of intact gliadin peptides via the transferrin receptor in celiac disease. J Exp Med 2008; 205 (1): 143-154.

5. Kubíková E, Mizeráková $P$, Cingel V, Labaš P, Šteňová J, Barčíková A, Beňuška J: Inervácia appendix vermiformis. 44. slovenský kongres patológov. Martin, 2009; 2-3.

6. Kleinschmidt S, Nolte I, Hewicker-Trautwein M. Structural and functional changes of neuronal and glial components of the feline enteric nervous system in cats with chronic inflammatory and non-inflammatory diseases of the gastrointestinal tract. Res Vet Sci. 2011 [Epub ahead of print] PubMed PMID: 21349562

7. Vetuschi A, Sferra R, Latella G, D'Angelo A, Catitti V, Zanninelli G, Continenza MA, Gaudio E. Smad3-null mice lack interstitial cells of Cajal in the colonic wall. Eur J Clin Invest 2006; 36 (1): 41-48.

Received August 15, 2011. Accepted March 8, 2014. 